\title{
Plastic-Free July: An Experimental Study of Limiting and Promoting Factors in Encouraging a Reduction of Single-Use Plastic Consumption
}

\author{
Lea Marie Heidbreder ${ }^{1, *(\mathbb{D}}$, Julia Steinhorst ${ }^{2}$ and Manfred Schmitt ${ }^{3}$ \\ 1 Interdisciplinary Research Group for Environmental Studies, University of Koblenz-Landau, \\ 76829 Landau, Germany \\ 2 Institute of Advanced Sustainable Studies, 14467 Potsdam, Germany; Julia.Steinhorst@iass-potsdam.de \\ 3 Personality, Psychological Assessment, and Psychological Methods, Department of Psychology, \\ University of Koblenz-Landau, 76829 Landau, Germany; schmittm@uni-landau.de \\ * Correspondence: heidbreder@uni-landau.de
}

Received: 19 March 2020; Accepted: 26 May 2020; Published: 9 June 2020

\begin{abstract}
To tackle the plastic problem, the worldwide campaign 'Plastic Free July' aims at encouraging people to reduce single-use plastics during the month of July. To get people started with new behavior patterns, so-called 'windows of opportunity' - periods where people become open for new experiences-are expected to matter. Therefore, the current study evaluated if an arbitrary month that is framed as an opportunity for change can interrupt people in their daily routines and reduce plastic consumption. An online survey $(n=509)$ with repeated measures $(n=366)$ was conducted including one experimental and one control group. The experimental group was invited to reduce their single-use plastic consumption during July in line with the 'Plastic Free July' campaign. Results revealed that, in this action period, single-use plastic consumption was slightly but significantly lower in the experimental than in the control group, which did not receive any information about 'Plastic Free July'. The campaign seemed to be more effective for participants with low pro-environmental identity. Path analysis revealed that plastic consumption (prior to the intervention) was significantly predicted by perceived difficulty, habits, and pro-environmental identity. Policy support was predicted by problem awareness, pro-environmental identity and perceived barriers. We conclude with recommendations for plastic-free purchase and policy support.
\end{abstract}

Keywords: single-use plastic; consumption; window of opportunity; pro-environmental identity; intervention

\section{Introduction}

In our affluent western society, we are facing an era of overconsumption [1], which is defined as the 'excessive use of goods and services' [2] (p. 28). Consumers can experience almost endless autonomy in shopping facilities, since a wide range of products are available to them. However, this range of products comes at the cost of huge environmental challenges along the whole product chain, from an intensive use of resources in the production process to waste from products that are no longer used. These side effects of overconsumption have increased citizens' awareness about plastic pollution as a predominant concern in the current debate of global environmental issues. In the last decades, the yearly production rate of plastic has reached almost 360 million tons [3]. It is estimated that, of the plastic waste ever generated, only $9 \%$ has been recycled [4], and 4.8 to 12.7 million tons end up in sea annually [5]. Thus, plastic particles can now be found even in remote areas of the world as well as in human bodies [6,7]. In particular, many different wildlife species suffers as animals die of entanglement and ingestion [7-9]. Economic costs are estimated at up to $\$ 33,000$ per ton of marine plastic per year [10]. 
In the last century, plastic has performed a triumph in manifold areas, making it ubiquitous in our daily life. However, as plastic is especially valued for its robustness, its long living character turns out to be the difficulty when it ends up in the ecosystem and stays there as waste for a long time. The current concern mainly focusses on single-use plastics with a short useful life and a fast, subsequent disposal. Single-use plastic objects mainly constitute packaging material, which causes one third of the global plastic production [3]. Packaging provides several functions, such as protection of food quality or attraction of consumers [11]. As a growing concern about plastic pollution in society is registered [12], alternatives to plastic bags, packaging, or plastic bottles are under discussion. The European Union has adopted a directive on the use of single-use plastics [13], and many nonprofit organizations have started campaigns to reduce the amount of plastics $[14,15]$. However, campaigns for a broad audience aiming at encouraging people to change their plastic consumption are rare and mostly not evaluated [15] — a gap in literature that we seek to fill with the present research.

In the following section, we will describe the theoretical framework on which our research builds. We begin with delineating prominent theories of environmental behavior that have inspired our framework and mention the constructs we have selected as part of that framework. Subsequently, we elaborate on these constructs, explain in depth the reasons for their selection and combination, and translate these reasons into hypotheses that our research sought to test. Next, we explain the application of the integrative theoretical framework to plastic consumption and policy support, the two outcomes we investigated. Finally, we provide an overview of the study we performed for testing the hypotheses.

\subsection{Integrative Theoretical Framework}

The current socioscientific research discusses a number of different drivers to encourage pro-environmental behavior [16] and suggests that multiple factors determine behavior change [17]. These factors are embedded in different theories and research traditions. We selected those factors from these theories and research traditions for an integrative theoretical framework that were found to be particularly effective in previous studies addressing pro-environmental behavior.

\subsubsection{Rational Choice Model}

A prominent approach to explain behavior change is rooted in rational choice theories [18], by which people are expected to weigh the costs and benefits of their behavior. This approach is represented by the theory of planned behavior (TPB) [19]. In line with this approach, our theoretical framework and study considered perceived difficulties and barriers as predictors of single plastic use. However, from a rational point of view, individuals do not always have greater benefit from showing pro-environmental behavior. Positive consequences of pro-environmental behavior are often delayed in time and space and might only take effect when it is collectively implemented. Nevertheless, people do act environmentally friendly. There is growing evidence that people do not only maximize rational criteria in their ecological behavior but also take moral considerations into account in their decision processes [20,21].

\subsubsection{Moral Choice Model}

Therefore, several researchers have proposed to expand the rational choice model with moral and normative factors [22], including the consideration of positive outcomes for others and the natural environment per se rather than oneself [23]. In line with this reasoning, our theoretical framework and study considered problem awareness and pro-environmental identity as predictors of pro-environmental behavior.

\subsubsection{Habit Model}

Beyond rational and moral choices, people also act in a more unconscious manner following their habits [24]. Habits are automatic behavior sequences that are often exercised without consciousness [25]. 
In fact, one main barrier that hinders people to try new behavior and should therefore be addressed in campaigns is their habits [26]. In the context of plastic use, habits were shown to be a key factor that influences plastic consumption [14]. Accordingly, our theoretical framework and study considered habits as predictors of pro-environmental behavior. To interrupt habits, periods of change in peoples' lives (e.g., moving to another city) were found to ease the establishment of new behavior [27]. However, these phases are rare and may differ in their intensity. Less intense phases of change, such as Lent [28], are understudied with regard to their potential of changing consumer behavior. Arbitrary periods, if appropriately framed as phases of change, might also work as a 'window of opportunity' where people change their consumption behavior. Accordingly, our theoretical framework and study considered such an arbitrary 'window of opportunity'.

\subsection{Constructs of the Integrative Theoretical Framework and Expected Effects on Pro-Environmental Behavior}

\subsubsection{Rational Choice Construct: Perceived Difficulty}

Perceived difficulty of a target behavior is an important predictor for behavioral change. External circumstances influence how easy or difficult it is for people to act environmentally friendly. Having a bus stop in front of one's door makes it easier to take public transportation, and having a zero-waste shop within manageable distance makes it easier to reduce plastic consumption. In his prominent theory of planned behavior, Ajzen [19] introduced the construct of perceived behavior control, which was a strong predictor for intention and behavior in meta-analyses [29,30]. According to Ajzen's original studies, perceived behavior control includes two subdimensions: the controllability over the performance of a certain behavior (How much control do I have?) and the perceived difficulty (How difficult is it for me to show this behavior?). In many studies, these subdimensions are mixed. However, Chan and Fishbein [31] showed that one might perceive a behavior as difficult but still feel to be in control of showing it (and vice versa). In a study by Cheung, Chan, and Wong [32], for example, perceived difficulty significantly predicted recycling intention, whereas perceived controllability did not. Thus, in this study we concentrated on perceived difficulty only and proposed the following hypothesis:

H1a: Perceived difficulty is negatively related to pro-environmental behavior.

\subsubsection{Rational Choice Construct: Perceived Barriers}

Perceived barriers are also an important variable that determines behavioral change. Although many people show a high willingness to act environmentally friendly, consumers in the western world have made slow progress in changing their behavior toward a more sustainable way [33]. Barriers that are objectively or subjectively beyond an individuals' control can prevent people from acting according to their normative standards, apart from psychological processes such as habits [34]. Perceived barriers and perceived difficulty are closely linked. Someone who perceives many barriers is more likely to evaluate his or her behavior as difficult. According to Schultz [16], barriers can be either structural (e.g., lack of plastic-free alternatives) or personal (e.g., lack of individual resources such as money or time). Both can paralyze pro-environmental behavior [33]. Therefore, we propose:

H1b: Perceived barriers are negatively related to pro-environmental behavior.

\subsubsection{Moral Choice Construct: Pro-Environmental Identity}

It is more likely to show pro-environmental behavior if someone considers him- or herself as an environmentally friendly person, and thus has a strong pro-environmental identity. Considering positive outcomes for others (or the environment) rather than oneself seems to motivate people to act environmentally friendly. For example, moral considerations were a predictor to buy products with an ecological label [35]. The crucial role of morality as a motivator for pro-environmental behavior was explained by people's aspiration to maintain a positive self-concept or identity [36,37]. According to 
Rise, Sheeran, and Hukkelberg [38], the self-concept or self-identity refers to individuals' perception of relevant attributes they possess. These attributes, in turn, reflect behaviors they prefer. People with strong pro-environmental identities try to be 'green rather than greedy' [39] (p. 1) and seek self-consistency by ensuring that their actions are in line with their elevated ecological standards [40-42]. Pro-environmental identity has been found to be predictive of pro-environmental behavior in different domains, such as sustainable consumption [43,44], carbon-offset [44], environmental activism [45], or recycling [46,47]. According to this, we propose:

H1c: Pro-environmental identity is positively related to pro-environmental behavior.

\subsubsection{Moral Choice Construct: Problem Awareness}

The fundament for consciously acting environmentally friendly is to be aware of ecological problems. According to the norm activation model (NAM, [23]) problem awareness can be defined as the perceived or anticipated violation of a normative standard. Problem awareness activates a sense of obligation to protect, affirm, and re-establish the violated or threatened standard. The model predicts that threats to or violations of ecological standards motivate pro-environmental behavior (see also [48]). In line with this prediction, a study by Whitmarsh, Capstick, and Nash [49] found environmental problem awareness to explain differences in willingness to reduce consumption between different countries. Therefore, we propose:

H1d: Problem awareness is positively related to pro-environmental behavior.

\subsubsection{Habits}

Habits are helpful in our daily life. They support us in overcoming the day without taking a decision in every little situation, weighing all advantages and disadvantages. However, when behavior change is pursued they can become an obstacle, as getting rid of a daily routine is very challenging [50]. In previous studies, habits were good predictors for pro-environmental behavior even beyond TPB and NAM [24,51,52]. In a meta-analysis reviewing pro-environmental behavior, habits have been emphasized as a key factor that should be incorporated in every comprehensive model [22]. Therefore, we propose:

H1e: Habits are negatively related to pro-environmental behavior.

\subsubsection{Habit Change During 'Windows of Opportunity'}

By definition, habits are characterized as recurring, automatic, and unconscious reaction on stable circumstances [25,53-55], and these stable circumstances are the decisive point when aiming to encourage behavior change (e.g., for environmental reason). A range of studies has shown that change of circumstances can give the impulse to break old and form new habits. For example, people who were forced by a construction site to change from car to bus were more often using the bus afterwards [56]. The same was found when Copenhagen car owners got a free month travel card: They increased their commuting by public transportation and an effect remained even five months later. The intervention was in particular effective when people had positive experiences with using public transportation [57]. Furthermore, it was shown that intervention for behavior change was most effective when people were in a phase of change anyway, like moving to another city or having a child. Promoting sustainable behavior was thus more effective when the target group consisted of people who recently moved [58]. Relocation was also a good phase to change travel-mode choices and reduce car travels [27,59-62]. Some other studies have focused on life-cycle-events $[54,63,64]$ or workplace relocation [65]. Even the fasting period has proven a good phase to reduce plastic consumption [28].

A prominent approach to explain this phenomenon is the habit discontinuity hypothesis $[62,65]$. It points to the destabilization of causal links between context cues and a behavioral response and thus 
provides an opportunity to break old habits and learn new ones. These phases are also called 'windows of opportunity' [54,66]. Interventions presented in these phases are expected to be particularly effective [67]. Based on the theoretical considerations above, we postulate:

H2: The creation and dissemination of campaigns based on a 'window of opportunity' are positively related to pro-environmental behavior.

\subsection{Application of the Integrative Theoretical Framework to Plastic Consumption and Policy Support}

A wide range of specific pro-environmental behaviors like mobility behavior [24], sustainable food consumption [68], or recycling [69] was examined so far. Despite a variety of studies on recycling, the reduction of plastic consumption as waste-related pro-environmental behavior has been addressed in very few studies only [14]. To fill this gap, we applied the proposed integrative theoretical model to plastic consumption and conducted a study to examine what encourages people to reduce their single-use plastic consumption in daily life.

In order to achieve an environmental goal, people can either change their individual behavior in the private sphere, such as by consumption, or they can engage in changes in the public sphere, e.g., by supporting political measures [70]. In a paper about consumer policy, Thøgersen emphasized that 'What matters is what large groups of consumers do' [33] (p. 145). Policy has the opportunity to empower consumers to change towards a sustainable lifestyle [66] and play a critical role in tackling environmental problems [71]. By offering information (e.g., eco-labelling) and removing structural barriers, consumers can be encouraged to make informed choices and implement their choices more easily. Pro-environmental behavior thus becomes less dependent of consumers' good will [66].

With regard to plastic pollution, only few studies have evaluated the effectiveness of policy measures in bringing about considerable change [72]. All over the world, governments have taken measures to reduce plastic with a particular focus on plastic bags, either with bans or economic instruments such as fees, levies, or taxes [73]. The implementation of a plastic bag levy $(0.15 €)$ in Ireland in 2002, for example, reduced the national plastic bag use by up to $90 \%$ [72]. While bans are obviously most effective looking at the outcome, they might be not feasible in every context and might provoke unintended reactions (e.g., reactance to regulation or use of even worse alternatives from an environmental outcome perspective) [14]. Thus, examining policy support and its predictors is crucial to encourage a reduction of plastic waste.

\subsection{The Present Study}

Responding to several research gaps, the present study pursued three related and novel research goals. First, our study will make a contribution to the literature by combining strong predictors of pro-environmental behavior and applying these predictors to the new field of plastic consumption. For this purpose, we propose a new framework which integrates constructs from prominent theories of pro-environmental behavior while simultaneously limiting the number of variables to an efficient minimum. The framework we propose combines constructs of rational choice theories (i.e., perceived difficulty, perceived barriers) and moral choice theories (i.e., pro-environmental identity, problem awareness) with habits and theories of habit change during 'windows of opportunity.' Including these constructs in a single study allows estimating their unique and joint effects on plastic consumption in a multivariate regression model.

Second, in order to explore whether the effects of the psychological predictors on plastic consumption can be generalized on public sphere behavior, we repeated the regression model for plastic consumption using policy support as a second outcome variable. Thus, the proposed hypotheses were tested for two forms of pro-environmental behavior: plastic consumption and policy support.

Third, the present study tested if opening a 'window of opportunity' for habit change will reduce plastic consumption and moderate the impact of variables from the integrative framework. For this purpose, we made use of the campaign 'Plastic Free July' (PFJ) (https://www.plasticfreejuly.org/). Started 
in Australia in 2011, this worldwide campaign encourages individuals from civil society to reduce single-use plastics during the month of July. We conducted an online survey with repeated measures (before and in July) including one experimental and one control group. According to the 'Plastic Free July', the experimental group was invited to reduce their single-use plastic consumption in July while the control group did not receive this invitation. In order to explore whether the effects of the psychological predictors on plastic consumption generalize across the two experimental groups or else vary across group membership, we tested group membership as a moderator of all predictors by including the relevant product terms in the regression model.

\section{Materials and Methods}

\subsection{Sample}

Participants were recruited via SoSciPanel, an open noncommercial survey portal where people can register for free to take part in scientific surveys [74]. As incentives, participants could win shopping vouchers in a lottery. Before July 2019, 509 participants of the German population completed an online survey and were randomly allocated to an experimental and a control group. The experimental group was comprised of 252 participants, and the control group contained 257. At the end of July, participants were asked to take part in a second survey. Three hundred and sixty-six participants filled out the second survey $(72 \%)$. Table 1 presents sociodemographic information for the experimental and the control groups in both surveys before and at the end of July. The experimental and the control groups did not differ in their sociodemographic characteristics.

Table 1. Sociodemographic data for the experimental and control group before $\left(\mathrm{n}_{1}=509\right)$ and at the end of July $\left(\mathrm{n}_{2}=366\right)$.

\begin{tabular}{|c|c|c|c|}
\hline & $\begin{array}{l}\text { Experimental Group } \\
\left(\mathrm{n}_{1}=252, \mathrm{n}_{2}=179\right)\end{array}$ & $\begin{array}{c}\text { Control Group } \\
\left(n_{1}=257, n_{2}=187\right)\end{array}$ & Group Comparison \\
\hline \multirow{2}{*}{ Age } & $M_{1}=42.85\left(S D_{1}=15.83\right)$ & $M_{1}=43.65\left(S D_{1}=16.00\right)$ & $\mathrm{t}_{1}(506)=-0.56, p=0.57$ \\
\hline & $M_{2}=43.77\left(S D_{2}=15.75\right)$ & $M_{2}=44.81\left(S D_{2}=16.42\right)$ & $t_{2}(363)=-0.62, p=0.54$ \\
\hline \multirow{3}{*}{ Gender } & $\mathrm{t} 1: 58 \%$ female & t1: $57 \%$ female & $\mathrm{F}_{1}(1,507)=0.11, p=0.74$ \\
\hline & t2: $56 \%$ female & t2: $58 \%$ female & $\mathrm{F}_{2}(1,364)=0.37, p=0.54$ \\
\hline & t1: $66 \%$ university degree & $\mathrm{t} 1: 65 \%$ university degree & \\
\hline \multirow{2}{*}{ Education } & $25 \%$ high school & $23 \%$ high school & $\mathrm{F}_{1}(1,507)=0.70, p=0.40$ \\
\hline & $\begin{array}{c}\text { t2: } 68 \% \text { university degree } \\
24 \% \text { high school }\end{array}$ & $\begin{array}{c}\text { t2: } 67 \% \text { university degree } \\
33 \% \text { high school }\end{array}$ & $F_{2}(1,364)=0.16, p=0.69$ \\
\hline \multirow{2}{*}{ Household size } & $M_{1}=2.38\left(S D_{1}=1.44\right)$ & $M_{1}=2.26\left(S D_{1}=1.16\right)$ & $t_{1}(507)=1.03, p=0.30$ \\
\hline & $M_{2}=2.40\left(S D_{2}=1.39\right)$ & $M_{2}=2.14\left(S D_{2}=1.09\right)$ & $t_{2}(364)=1.93, p=0.05$ \\
\hline \multirow{2}{*}{ City } & t1: $44 \%$ large city & t1: $51 \%$ large city & $\mathrm{F}_{1}(1,364)=0.82, p=0.37$ \\
\hline & t2: $44 \%$ large city & t2: $52 \%$ large city & $\mathrm{F}_{2}(1,364)=1.33, p=0.25$ \\
\hline \multirow{2}{*}{ Holiday plans for July } & t1: $22 \%$ yes & t1: $25 \%$ yes & $\mathrm{F}_{1}(1,364)=0.67, p=0.41$ \\
\hline & t2: $21 \%$ yes & t2: $26 \%$ yes & $\mathrm{F}_{2}(1,364)=1.25, p=0.27$ \\
\hline
\end{tabular}

\subsection{Procedure and Intervention}

All participants gave their informed consent for inclusion before they participated in the study. The study was conducted in accordance with ethical standards. In order to explore changes in behavior, two surveys (before and at the end of July) were scheduled. In the first survey, participants were randomly divided into an experimental and a control group. The control group filled out the survey without any further information. The experimental group received information about the campaign 'Plastic Free July' and problems of plastic pollution. They were informed that, since 2011, millions of people take part in the challenge to reduce single-use plastic during the month of July. It was pointed out that one-third of the global plastic production can be traced back to packaging, and plastic waste in the environment can harm wildlife and pollute beaches. Participants were invited to participate in the challenge of reducing single-use plastic consumption in July. In a second step, participants 
received ten pieces of advice on how to reduce plastic consumption presented with photos (e.g., taking a bag or rucksack, buying milk or yoghurt in a glass container). Participants could then rate if they were willing to put the advice into practice in July (yes, maybe, no) or if they were doing it already. Furthermore, their intention to participate was measured by approval to the statement 'I plan to reduce my plastic consumption in July' on a five-point Likert scale (from 1-'strongly disagree' to 5-'strongly agree'). The intention to participate in the challenge to reduce single-use plastic consumption in July was $M=3.49(S D=1.07)$.

\subsection{Manipulation Check}

In the second survey at the end of July, a manipulation check was included. The statement 'For me, July was a good opportunity to try new plastic-free alternatives' was rated on a five-point Likert scale (from 1-'strongly disagree' to 5-'strongly agree'). It should explore if people perceived the month of July as a special month, according to the idea that a 'window of opportunity' can break old habits. People in the experimental group did not perceive July as a more special month, as pairwise-t-test showed no difference in perceptions between the experimental and control groups $(t(364)=-0.255$, $p=0.80, d_{\mathrm{Coh}}=0.025, M_{\mathrm{E}}=2.26, M_{\mathrm{C}}=2.29$ ). However, those who perceived July as a good opportunity for plastic-free consumption also stated to have consumed less plastic in July $(r=-0.29)$. Furthermore, to check if participants were familiar with the concept of PFJ, they were asked if they had heard about it before; $95 \%$ of the control group had never heard about the campaign of PFJ before.

\subsection{Measures}

All items of both surveys can be found in the Appendix A. In both surveys, participants completed a questionnaire about plastic consumption. In the first survey before July only, they filled out further questions about habits, perceived difficulty, pro-environmental identity, and problem awareness. In the second survey at the end of July, participants filled out further questions about policy support and perceived barriers. The separation of constructs was made to shorten each survey.

\subsubsection{Plastic Consumption}

Plastic consumption was measured in two surveys, before and at the end of July. Participants were presented with ten categories for daily consumer goods (e.g., fruits and vegetables, fresh products, dry products) and were asked which of these products they had consumed during the last week. To make retrieval easier, for all selected products, up to five items (e.g., bread or cake for pastries) were presented as subcategories and participants had to rate if they had consumed it with plastic packaging (1-'all without plastic,' 2-'partially in plastic,' 3-'all with plastic' or 'not bought at all'). For the general score, items with the rating 'not purchased at all' were excluded and a mean score of all remaining items was calculated $\left(\alpha_{1}=0.66, \alpha_{2}=0.69\right)$.

\subsubsection{Policy Support}

Support for different policy steps (e.g., ban or tax of single-use plastic products, deposit system for to-go packaging) was assessed using five-point Likert scales (from 1-'strongly disagree' to 5-'strongly agree'). A mean score over all items was calculated $(\alpha=0.78)$. Using the same response scale, one further item asked if political measures would limit personal freedom.

\subsubsection{Perceived Difficulty}

The same product categories as in the general measure of plastic consumption were used to examine the perceived difficulty of plastic-free consumption. All ten categories were rated on a five-point Likert scale (from 1-'It's easy for me' to 5-'It's hard for me') with regard to the perceived difficulty of plastic-free purchase in daily life. A mean score over all items was calculated with higher scores indicating that people find it hard to buy products without plastic $(\alpha=0.73)$. 


\subsubsection{Perceived Barriers}

To examine what impedes plastic-free consumption, eight potential barriers (e.g., missing offers of plastic-free alternatives, higher costs, time effort) were presented, and participants could decide if these options were a barrier in their daily life and then rank them. The number of chosen barriers served as barrier score. A higher score indicated more perceived barriers.

\subsubsection{Pro-Environmental Identity}

A single-item measure was used for capturing pro-environmental identity. On a five-point Likert scale (from 1-'strongly disagree' to 5-'strongly agree'), participants responded to the statement 'I see myself as an environmental conscious person.'

\subsubsection{Problem Awareness}

Based on the representative survey of the German Federal Environmental Agency [75], problem awareness was measured with a five-point Likert scale (from 1-'no problem' to 5-'very big problem'). Participants had to assess several problems (e.g., plastic waste in the ocean, species extinction through plastic in the environment, health impairment caused by plastic). A mean score over the eight items was calculated $(\alpha=0.80)$.

\subsubsection{Habits}

Measurement of consumption habits was based on a German version of the Self-Reported Habit Index (SRHI) of Verplanken and Orbell [76]. The SRHI assesses different features of habits like automaticity, experience of frequency, and unconsciousness. In comparison to the original twelve-item scale, items with a time context (e.g., 'I have been doing for a long time') were not included in this study because the study referred to a short time frame where potential habits change could be observed not in the long run. The shortened version applied to the habits to buy products without plastic. Eight items completing the stem 'To buy products without plastic is something...' represented the different features of habits (e.g., I do without thinking, I do automatically) and were rated on a five-point Likert scale (from 1-'strongly disagree' to 5-'strongly agree'). For each participant, the SRHI responses were averaged into an aggregated habits index $(\alpha=0.67)$ with high scores indicating strong habits.

\subsection{Statistical Analysis Methods}

In order to test if the creation and dissemination of campaigns based on a 'window of opportunity' were positively related to pro-environmental (H2), we assumed that single-use plastic consumption before July decreases in July in the experimental group while it rests stable in the control group. Therefore, we conducted a mixed-model ANOVA. With an ANOVA, we could examine differences in plastic consumption between the groups and over time. A mixed model was used as group differences were measured between different participants (between-subject factor) and the change in plastic consumption over time was measured within a person (within-subject factor). To statistically test the equality of means, ANOVA uses $F$-tests. When the $p$ value of $F$ is smaller than 0.05 , we reject the null hypothesis. In addition to $F$ and $p$, we report the partial eta $\eta^{2}$ p as effect size coefficients. Subsequently, we used post hoc $t$-tests with Bonferroni correction for the pairwise comparison of means. As effect size we report Cohen's $d$ here.

To examine which psychological variables predict pro-environmental behavior (H1a-e) in form of plastic consumption and policy support, we estimated the parameters of a linear path model based on multiple regression analyses. Standardized path coefficients indicate the strength of the relations between the independent and dependent variable with higher numbers indicating stronger relations. $R^{2}$ is the coefficient of determination indicating the proportion of variance of the dependent variables explained by the independent variables. Model fit was determined to detect misspecifications of the model, such as omitted interactions or nonlinear effects. The Chi-Square $\left(X^{2}\right)$ 
test assesses overall model fit but is sensitive to sample size. The Comparative Fit Index (CFI) compares the target model with an independent baseline model. The Root Mean Square Error of Approximation (RMSEA) and the Standardized Root Mean Square Residual (SRMR) indicate the discrepancy between the empirical covariance matrix and the covariance matrix implied by the estimated parameters of the model. For a good model fit, CFI should be greater than 0.90 and RMSEA and SRMR smaller than 0.08 , at least [77].

We conducted all analyses with $\mathrm{R}$ (version 3.6.1) and used the packages psych [78] for descriptive analyses and correlations, dplyr [79] for preparation of data, lavaan [80] and sem [81] for path models. As descriptive statistics, we computed means (M) and standard deviations (SD) for continuous variables and report these values in parentheses as mean \pm standard deviation. Raw data can be found in the Supplementary Materials.

\section{Results}

\subsection{Descriptive Results}

\subsubsection{Perceived Difficulty}

Participants perceived it as rather difficult to buy products without plastic $(3.10 \pm 0.65)$, see also Table 2 for means and standard deviations of all variables separately for each group. Considering the item level, pastries $(1.92 \pm 1.17)$ as well as fruits and vegetables $(2.09 \pm 1.18)$ were products that were rated as easiest to buy plastic free, while cosmetics $(4.13 \pm 1.23)$ and household products $(4.31 \pm 1.07)$ were rated as most difficult.

Table 2. Means and standard deviations separately for each group.

\begin{tabular}{ccccc}
\hline & \multicolumn{2}{c}{ Experimental Group $(\boldsymbol{n}=\mathbf{1 7 9})$} & \multicolumn{2}{c}{ Control Group $(\boldsymbol{n}=\mathbf{1 8 7})$} \\
\hline & $\boldsymbol{M}$ & $\boldsymbol{S D}$ & $\boldsymbol{M}$ & $\boldsymbol{S D}$ \\
\hline Plastic consumption before July & 2.05 & 0.33 & 2.09 & 0.34 \\
Plastic consumption in July & 2.01 & 0.34 & 2.10 & 0.34 \\
Policy support & 3.67 & 0.87 & 3.66 & 1.03 \\
Perceived difficulty & 3.11 & 0.67 & 3.08 & 0.63 \\
Perceived barriers & 6.20 & 2.42 & 6.36 & 2.44 \\
Pro-environmental identity & 3.87 & 0.80 & 3.84 & 0.77 \\
Problem awareness & 4.20 & 0.63 & 4.20 & 0.61 \\
Habits & 2.98 & 0.63 & 2.92 & 0.60 \\
\hline
\end{tabular}

Note: The scales of plastic consumption ranged from 1 to 3 ; the number of perceived barriers ranged from 0 to 8 ; the scales of the further variables ranged from 1 to 5 .

\subsubsection{Perceived Barriers}

Overall, $60 \%$ of participants chose all eight proposed options as a barrier. A missing offer of plastic-free alternatives was rated by far the highest barrier that hinders participants to purchase less products with plastic. Almost all participants chose it as a barrier and $81 \%$ ranked it as the most important one. About $79 \%$ of the sample perceived higher costs, an inconvenient transport, and expenditure of time to be barriers, which were mostly ranked on the second to fourth place. Still 70\% ranked missing hygienic and limited shelf life as a barrier. The least important barriers that participants indicated were the purchase behavior of people in their close environment $(65 \%)$ and too much interaction with the salesmen (64\%).

\subsubsection{Pro-Environmental Identity}

Many participants ascribed themselves to have a pro-environmental identity (3.85 \pm 0.78$) ; 20 \%$ strongly agreed to be an environmental conscious person, $50 \%$ did so partly. Only $4 \%$ partly or strongly disagreed to this statement. 


\subsubsection{Problem Awareness}

Participants expressed a generally high problem awareness towards problems related to plastic $(4.21 \pm 0.61)$. Plastic waste in the ocean and species extinction were seen as the biggest problems, with $98 \%$ and $91 \%$ rating these issues as rather or very large problems. Plastics in soil (83\%) and energy and resource depletion $(77 \%)$ were also indicated as rather or very large problems. Topics with a direct link to the person (health impairment by plastics and aesthetic burden by plastic pollution) were rated as problematic by $70 \%$ and $75 \%$ of participants. Increase of climate change and social problems due to plastic were seen at least problematic: $67 \%$ and $65 \%$ rated it as a rather or very large problem.

\subsubsection{Habits}

Habits to buy products without plastic were rated on a medium level $(2.95 \pm 0.61)$. Exceedingly few indicated to start doing so before realizing it $(2.48 \pm 1.12)$ or doing it without consciously remembering (2.56 \pm 1.19$)$. Most approval was given to the statements 'that's typically me' $(3.03 \pm 1.12)$ and 'that makes me feel weird' ( $4.54 \pm 0.86$, recoded), indicating that the automaticity of plastic-free purchase was not strongly internalized, unlike an identification with such a behavior.

\subsubsection{Plastic Consumption}

Overall, participants had a medium level of plastic consumption before July ( $2.07 \pm 0.33)$. Considering the item level, snacks ( $2.58 \pm 0.59)$, cosmetics $(2.56 \pm 0.51)$, fresh products $(2.50 \pm 0.48)$, and household goods $(2.47 \pm 0.55)$ were mostly bought with plastic, while fruit and vegetables $(1.64 \pm 0.52)$, food to go $(1.51 \pm 0.57)$, and bakery products $(1.51 \pm 0.62)$ were bought with less plastic.

\subsubsection{Policy Support}

Policy support was moderately high (3.66 \pm 0.95$)$. Overall, $61 \%$ disagreed or rather disagreed to feel limited in their personal freedom because of political instructions, whereas $17 \%$ agreed or rather agreed to this. Regarding concrete measures, $77 \%$ appreciated a ban of single-use plastic and $70 \%$ would support a tax on this. In addition, $70 \%$ agreed to use a deposit system for a container of sausage or cheese counter and $62 \%$ to use one for to-go products. Regarding transparency, $67 \%$ would account a label indicating plastic-free products in all their purchase decisions and $37 \%$ would use an app for this.

\subsection{Testing Hypothesis 2: Effectiveness of the Intervention}

The effect of the 'Plastic Free July' intervention on plastic consumption (H2) was evaluated via a mixed-model ANOVA with all participants who had filled out both surveys. Plastic consumption was the dependent variable and time (two measurement points) was the within-subject factor and group (experimental and control group) was the between-subject factor. The results revealed no main effect of time on plastic consumption $\left(F \times(1.363)=1.348, p=0.246, \eta^{2} p<0.001\right)$; thus, taking all participants into consideration, the plastic consumption did not change from the first survey (before July) to the second one (at the end of July). There was, however, a marginal main effect of group on plastic consumption $\left(F \times(1.363)=3.806, p=0.052, \eta_{p}^{2}=0.008\right)$, indicating that the plastic consumption tended to be lower in the experimental group than in the control group over both surveys. No interaction effect was found $\left(F \times(1.363)=2.692, p=0.101, \eta^{2} \mathrm{p}=0.001\right)$.

As we assumed directional effects, a Type 1 error risk of $\alpha=0.1$ was chosen for post hoc tests, which corresponds to the conventional significance level of $\alpha=0.05$ in two-tailed tests. Post hoc tests with Bonferroni correction showed no difference between the groups before the intervention but after the intervention (see Table 3), indicating that the experimental group used less plastic in July than the control group. Pairwise t-test revealed no difference between the two measurement points in the control group but a small effect in the experimental group, indicating that the experimental group reduced their plastic consumption in July. Overall, the second hypothesis (H2) regarding the effect of the 'Plastic Free July' challenge was confirmed. At the end of July, single-use plastic consumption 
was slightly higher in the control than in the experimental group. Participants in the experimental group somewhat reduced their single-use plastic consumption compared to before the intervention. By contrast, the plastic consumption of the control group remained stable.

Table 3. Results of the Bonferroni post hoc tests for plastic consumption $(n=366)$.

\begin{tabular}{clllllc}
\hline & & & $\boldsymbol{t}$ & $\boldsymbol{d f}$ & $\boldsymbol{p}$ & $\boldsymbol{d}$ \\
\hline t1: EG vs. CG & $M_{1, \mathrm{EG}}=2.05$ & $M_{1, \mathrm{CG}}=2.09$ & -0.99 & 363 & 0.323 & 0.119 \\
t2: EG vs. CG & $M_{2, \mathrm{EG}}=2.01$ & $M_{2, \mathrm{CG}}=2.10$ & -2.42 & 363 & 0.016 & 0.232 \\
EG: $\mathrm{t} 1$ vs. t2 & $M_{1, \mathrm{EG}}=2.05$ & $M_{2, \mathrm{EG}}=2.01$ & 1.73 & 178 & 0.085 & 0.128 \\
CG: t1 vs. t2 & $M_{1, \mathrm{CG}}=2.09$ & $M_{2, \mathrm{CG}}=2.10$ & -0.40 & 185 & 0.687 & 0.042 \\
\hline
\end{tabular}

Note: $\mathrm{EG}=$ experimental group, $\mathrm{CG}=$ control group, $\mathrm{t} 1=$ before July, $\mathrm{t} 2 \mathrm{=}$ at the end of July.

\subsection{Testing Hypotheses H1a—H1e: Predictors of Single-Use Plastic Consumption}

As a precondition for analyzing the impact of predictors on plastic consumption, correlations between all measured variables were analyzed separately for each group (Table 4). In both groups, a strong correlation between plastic consumption before and at the end of July was found, indicating a substantial stability of individual differences in plastic consumption over time. Of note, the stability of plastic consumption was lower in the experimental group than in the control group, suggesting that the treatment did not affect the members of the experimental group equally but differentially. Among the other variables, perceived difficulty showed the strongest correlation with plastic consumption in both groups. Thus, the more participants perceived it difficult to buy products without plastic packaging, the less they did so. Habits to buy products without plastic were negatively correlated with plastic consumption. While the correlation of habits and plastic consumption was the same in both groups before July, the correlation at the end of July was lower in the experimental group than in the control group. This indicates that former habits were less relevant after the intervention in the experimental group. Policy support showed medium-to-strong correlation with problem awareness and pro-environmental identity. Policy support and plastic consumption were negatively correlated on a low level.

Table 4. Correlations separately for each group.

\begin{tabular}{|c|c|c|c|c|c|c|c|c|}
\hline & PC1 & PC2 & PS & PD & PB & EI & PA & HB \\
\hline$P C 1^{a}$ & & 0.54 & -0.20 & 0.55 & 0.15 & -0.34 & -0.18 & -0.39 \\
\hline$P C 2^{b}$ & 0.75 & & -0.26 & 0.38 & $-0.03 *$ & -0.19 & -0.13 & -0.18 \\
\hline $\mathrm{PS}^{\mathrm{b}}$ & -0.18 & -0.13 * & & -0.14 * & -0.11 & 0.34 & 0.45 & 0.15 \\
\hline $\mathrm{PD}^{\mathrm{a}}$ & 0.52 & 0.47 & $-0.06^{*}$ & & 0.09 * & -0.23 & -0.19 & -0.38 \\
\hline $\mathrm{PB}^{\mathrm{b}}$ & 0.07 * & 0.05 * & -0.17 & 0.07 * & & 0.01 * & -0.08 * & 0.16 \\
\hline $\mathrm{EI}^{\mathrm{a}}$ & -0.35 & -0.36 & 0.29 & -0.28 & -0.20 & & 0.24 & 0.27 \\
\hline $\mathrm{PA}^{\mathrm{a}}$ & -0.30 & -0.26 & 0.43 & -0.21 & -0.14 & 0.35 & & 0.16 \\
\hline $\mathrm{HB}^{\mathrm{a}}$ & -0.40 & -0.28 & 0.19 & -0.48 & -0.02 * & 0.34 & 0.29 & \\
\hline
\end{tabular}

Note: Above diagonal: experimental group $(n=179)$; below diagonal: control group $(n=187) ;{ }^{a}$ measured before intervention, ${ }^{\mathrm{b}}$ measured after intervention; PC: plastic consumption before and at the end of July; PS: policy support; PD: perceived difficulty; PB: perceived barriers; EI: pro-environmental identity; PA: problem awareness; HB: habits; * insignificant.

To test the unique impact of the psychological variables considered on plastic consumption and policy support (H1a-e), we conducted a path model with data of participants who had filled out both surveys. In the path model, habits, perceived difficulty, pro-environmental identity, problem awareness, and perceived barriers were included as independent variables to predict the two dependent variables plastic consumption before and in July as well as policy support. Except for perceived barriers and problem awareness, all independent variables were measured in the first survey before the intervention. As perceived barriers and problem awareness did not differ between the two groups, we assumed no treatment bias and integrated them as predictors in the model. In addition, group 
and plastic consumption before July were included as predictors of plastic consumption in July. Controlling plastic consumption before July is necessary to reveal how much of the variance of plastic consumption in July which is not due to the stability of plastic consumption can be explained by the remaining predictors. It allows separating direct effects of the remaining predictors of plastic consumption in July from indirect effects of these predictors, with plastic consumption before July being the mediator. We also tested group membership as a moderator of all predictors by including the relevant product terms in the regression model. Group membership (dummy variable) was coded such that a value of 0 was assigned to the experimental group and a value of 1 to the control group.

The model (see Figure 1 ) had a good fit $\left(X^{2}(9)=4.082(p=0.906)\right.$, CFI $=1.00$ RMSEA $<001$ [0.000; 0.024], SRMR = 0.009). Supporting hypotheses H1a, H1c, and H1e, perceived difficulty, habits, and pro-environmental identity were significant predictors of plastic consumption before July. However, perceived barriers (H1b) and problem awareness (H1d) were not. In total, the predictors explained $35 \%$ of the variance of plastic consumption before July. Perceived difficulty was the strongest predictor for plastic consumption before July. Concerning plastic consumption in July, prior plastic consumption was the strongest predictor. Group and perceived difficulty also had direct effects. Habits, pro-environmental identity, problem awareness, and perceived barriers were no direct predictors for plastic consumption in July. An interaction effect was found between pro-environmental identity and group, which indicates that plastic consumption in July differed between the two groups in dependence of pro-environmental identity. The interactions between group and the other predictors were not significant. In total, the model explained $45 \%$ of the variance of plastic consumption in July.

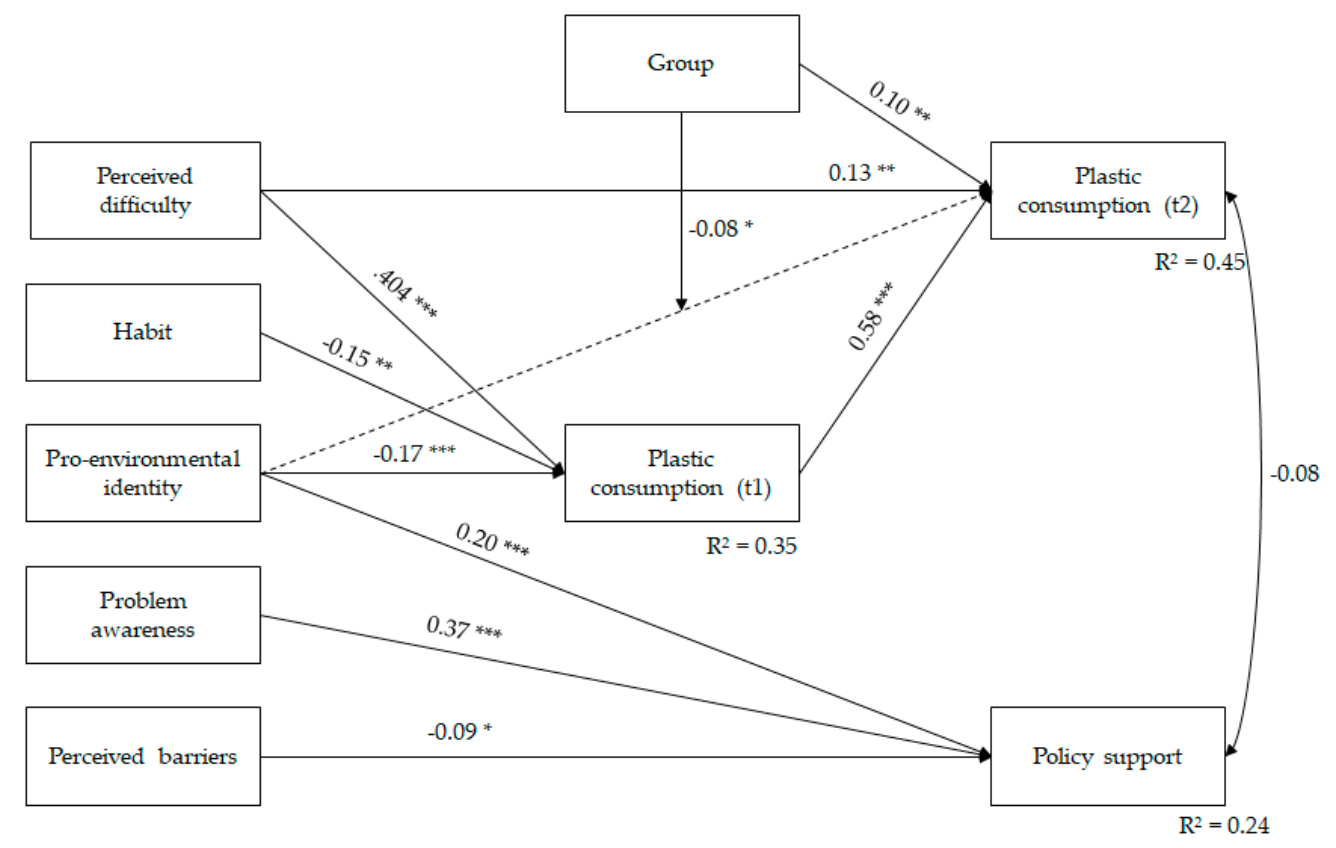

Figure 1. Results on predictors of single-use plastic consumption before and in July and policy support $(n=366)$; only significant standardized path coefficients are shown $\left(^{*}:<0.05,{ }^{* *}:<0.01,{ }^{* * *}:<0.001\right)$.

Policy support was predicted by problem awareness, pro-environmental identity, and perceived barriers. People who had a strong pro-environmental identity and a high problem awareness and who perceived more barriers in plastic consumption were more likely to support politics. Together, the three variables explained $24 \%$ of the variance of policy support. Policy support and plastic consumption at the end of July were slightly correlated $(r=-0.19)$.

To explore the interaction between group and pro-environmental identity in more detail, we conducted t-tests. For participants with a strong pro-environmental identity (above the mean), the experimental and control groups did not differ in plastic consumption in July $(t(252)=-0.126$, 
$p=0.21, M_{\mathrm{E}}=1.97, M_{\mathrm{C}}=2.02, d_{\mathrm{Coh}}=0.150$ ). For those with weak pro-environmental identity (below the mean), participants in the experimental group purchased less plastic than participants in the control group $\left(t(109)=-0.313, p<0.05, d_{\mathrm{Coh}}=0.621, M_{\mathrm{E}}=2.10, M_{\mathrm{C}}=2.29\right)$. Thus, we found evidence that the intervention was only effective for participants with low pro-environmental identity (see Figure 2).

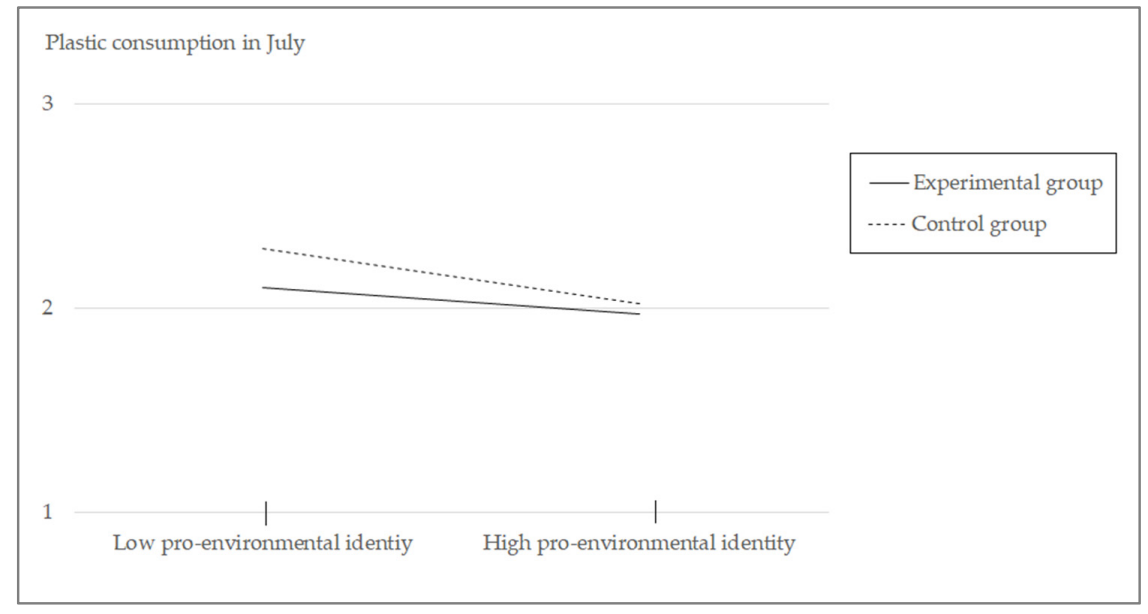

Figure 2. Interaction effect of pro-environmental identity and group allocation on plastic consumption in July.

\section{Discussion}

This study analyzed if people reduce their single-use plastic consumption when the month of July is presented as an action month for behavior change in plastic purchase. Results revealed that participants to whom the idea of 'Plastic Free July' was presented used slightly, but significantly less plastic than those without any intervention. However, the intervention was more effective for participants with low pro-environmental identity, as group differences for plastic consumption in July were only found among participants with low pro-environmental identity. This indicates the importance of considering the target group to increase the effect of a campaign. The strongest predictor for initial plastic consumption before the intervention was the perceived difficulty of plastic-free purchase. Perceived difficulty also remained a stable predictor of plastic consumption during the intervention. This coincides with the result that the strongest barrier named by study participants was a perceived lack of plastic-free alternatives. This means that, in order to enable consumers to reduce their plastic consumption, barriers should be reduced and more plastic-free alternatives should be created.

Policy support was more likely when people had a strong pro-environmental identity, when they showed high problem awareness concerning plastic pollution, and when they perceived being exposed to external barriers of plastic consumption. Thus, a normative concern appears to be an important base to support policy regulation. Note that perceived difficulties and habits, which were strong predictors of plastic consumption, did not predict policy support. This result is highly plausible, because the difficulties in buying plastic free and habits in plastic consumption are theoretically relevant for plastic consumption but not for policy support. By contrast, moral and normative concerns as reflected in pro-environmental identity are relevant for both outcomes.

The strong role of perceived difficulty to predict plastic consumption is similar to other studies in the context of pro-environmental behavior by which the perceived behavior control was a prominent predictor of different ecological behaviors [30]. However, when having a closer look at specific barriers that impede plastic consumption, they slightly differ from other pro-environmental consumption patterns, such as purchasing organic food. While the price was the strongest barrier to consuming organic food [82-84], it appears to be only in a second place for plastic-free purchase. In addition, missing offers of plastic-free alternatives were by far the strongest barrier for plastic-free purchase, while availability of organic food was only a barrier for one-third in a Polish sample [82] and was 
considered to be improved in Norway in the last decade [84]. While organic food is available in ordinary supermarkets in the meanwhile, plastic-free consumption often requires new purchase patterns associated with more time effort, an inconvenient transport, and more interaction with the seller. Furthermore, conflicts between different ecological criteria, such as the choice between plastic waste versus food waste [85], which has been perceived as a barrier in the form of limited shelf life in this study, makes the reduction of plastic packaging a more complex issue. It implies the need for more convenient and ecofriendly solutions in plastic-free consumption offers.

\subsection{Periods of Change}

Framing a random month as a period of change for plastic consumption revealed significant effects and reduced single-use plastic consumption in the experimental group. However, these effects were quite small. Different explanations for this finding are plausible.

First, the intervention used information including a short problem description and practical advices on how to reduce single-use plastic. When performing habitual behavior such as consumption pattern, incoming information can be suppressed when not fitting one's habitual behavior [86,87]. A campaign solely based on information can thus struggle to change habitual behavior. Although this intervention exceeded an information campaign, information was a focal point and might have reached only subgroups of participants.

Second, the main idea of the intervention was to create a 'window of opportunity' by framing a month as an action period of change. In previous studies, successful 'windows of opportunity' (e.g., moving to another city or having a child) were characterized by an obviously salient and inherent change [54]. This was not given in the present intervention as the period of change was only based on construction of thought. While this has successfully worked for the fasting period where people reduced their plastic consumption in the 40 days before Easter [28], July as an action month for change might be less embedded in tradition and people's minds. This interpretation is supported by the result that those participants who had perceived July as a good opportunity for change reduced their plastic consumption somewhat stronger. In consequence, one might need to make change more salient in such a random period. About $65 \%$ perceived it as a barrier that their close environment did not purchase plastic-free. This means, the presence of other people also taking part in a challenge might be crucial to make change salient. Future studies could explore the role of social and societal norms for creating a 'window of opportunity.'

Third, habits are reactions to stable circumstances (e.g., routinely doing weekly groceries in a supermarket that is situated on the way home). To break old habits, it is decisive to change such stable circumstances. The present intervention did not change such physical circumstances. Considering the mentioned barriers in the present study (e.g., time effort, missing offers), the restructuring and implementation of a new plastic-free section in the supermarket would eliminate such barriers while sparing changes of the shopping location. Simultaneously, the new presentation of products can interrupt routines of purchase by changing the circumstances within the supermarket. As the stable circumstances are not well specified in the current literature [53], a combination of physical change of circumstances (e.g., new sections in supermarket) and change in mindset of the situation (e.g., fasting period or action month) as well as the process behind should be evaluated in future research.

\subsection{Limitations}

The intervention used in the present study was similar, but not identical to the original campaign 'Plastic Free July'. Thus, this study did not serve as an evaluation of the original campaign nor did it measure impact in the form of reduced plastic waste. It rather picked up the idea of a random action month and evaluated if people who have not heard of this idea before would change their behavior accordingly. In the original campaign, people gain access to a website where they can interact with others and get information about plastic pollution and action steps. One can expect that people taking part in such a challenge are already intrinsically motivated to change their plastic consumption. 
In this study, information material about action steps were based on the original Plastic Free July campaign but were presented to the participants only once. Thus, it seems reasonable that the present intervention has created only small effects.

Furthermore, the manipulation check failed as participants in the experimental group did not perceive July as a more special month than participants in the control group. This suggests that, in future applications of the treatment for research or intervention purposes, a more explicit frame of the upcoming 'window of opportunity' as a special time or a transition period might be advantageous and strengthen the treatment effect. However, this recommendation is conditional upon the validity of the validation check item we employed. Its significant correlation with plastic consumption in July $(r=-0.29)$ suggests some validity. Nevertheless, the item was probably not designed sufficiently well as it required an abstract interpretation of participants (i.e., perception of a good phase of change) rather than testing differences between the groups given by the intervention material. It might have been better to ask for differences in knowledge about information that was given only to the experimental group.

Scale reliability was somewhat low for plastic consumption and habits $(<0.70)$. Note, however, that low reliability can go along with sufficient validity if a relatively short measure is used for a broad construct including different facets. Pro-environmental identity, on the other hand, was measured with a single item only. This was due to economic reasons. Note, however, that despite this limitation, pro-environmental identity was a significant predictor of both outcome variables. Nevertheless, we suggest to use a multiple-item scale in future studies (e.g., the Environmental Identity Scale [88]) to replicate the interaction effect between group affiliation and pro-environmental identity.

Another limitation might lay in the time period itself. As July is predestinated for holidays (one fourth stated to have holiday plans during this period in this study), it might have counteracted the intervention. As holidays are kind of special periods during the year, people might have more difficulties to live with less plastic being in another country with even less opportunities or the feeling of less responsibility during this time of the year [89]. On the other hand, when the study was conducted, media attention towards the topic of plastic pollution (and, in accordance, problem awareness) was quite high and might have supported an overall willingness to reduce plastic consumption. Note, however, that the intervention effects cannot have been biased by prior knowledge of the campaign, since the idea of a 'Plastic Free July' was unknown by $95 \%$ of participants in the control group.

Looking at the behavioral output of this study, some might also argue that a solution offering only small actions steps (e.g., taking a rucksack instead of a plastic bag) is not that noteworthy. Taking lifestyle (e.g., zero-waste lifestyle) into account might have a bigger environmental impact [90,91]. However, the feeling of being capable to show a certain behavior is quite important, and presenting concrete action steps seemed to be effective for people with low environmental consciousness at least. Further studies should examine if the technique of 'foot-in-the-door' [92] might work for plastic-free purchase, starting with small steps to get people to comply with larger challenges.

\subsection{Implications}

Although the intervention in the present study was not able to encourage great leaps of behavioral change, people with low pro-environmental identity who were less prone to a zero-waste lifestyle moved their plastic consumption towards those with a high pro-environmental identity, when they were in the experimental condition. This might indicate that this kind of 'low-threshold' intervention based on one practical advice can have an impact on a less concerned target group which is often difficult to reach. Furthermore, people in different behavioral stages might need different interventions to progress [93]. While people with high intention to reduce plastic (which can be expected from people with high pro-environmental identity) need support in planning and implementing their goals, people who have not generated such a strong will might already show progress by awareness campaigns and 'low-threshold' advices as employed in the present study. Presumably, different target groups experience different barriers and respond differently to information-based interventions [34]. 
Overall, participants indicated a high problem awareness regarding plastic pollution which corresponds to surveys of the general public [75,94]. As plastic-related problems, such as marine pollution and loss of biodiversity, were rated as more severe than health impact or aesthetic burdens of plastic pollution, persuasive communication aiming to change people's attitude might more focus on topics of ecological impact rather than personal consternation. Same as for problem awareness, the approval rate for policy support was quite high and problem awareness served as an important predictor for policy support. This means that that we face a 'window of opportunity' that makes change in political regulations and offers quite profitable, as high acceptance of consumers can be expected. Thereby, policy support was independent of consumers' own behavior. Retailers and politics should take advantage of this high problem awareness and policy support in public. In particular, the results of the present study show that bans and taxes were highly accepted. Having the ecological impact in mind, offering ecological alternatives is likewise important. A ban of plastic bags could lead to an increase of other bags that are not even better but perceived as more ecological friendly [95]. This misdirection has to be considered when banning plastic products. Offering ecological friendly alternatives (which might also be a complete removal of plastic packaging) and providing appropriate information are decisive. Referring to information, an app that labels plastic-free products was only supported by one-third of participants. A reason for this might be a shift of responsibility from consumers towards political regulations. An app would offer more transparency but still leaves consumers in the responsibility to choose a product.

Although consumers are offered a variety of choices for their purchase, in terms of plastic-free packaging, oftentimes, there is a lack of alternatives. In addition, $75 \%$ in the present study's sample indicated time and costs as a barrier for plastic-free purchase. Thus, the crucial point is to make convenient plastic-free offers available in an appropriate price framework and as little time-consuming as the original product [96]. Good alternatives should become available in habitual shopping facilities such as supermarkets. Moreover, the demand for hygiene should be considered. Although it was not mentioned as the most relevant barrier, the majority of participants mentioned hygiene as a barrier of middle range. In addition, people were cautious with regard to plastic-free alternatives in the hygienic area (e.g., using a wooden toothbrush). This means that product marketing of plastic-free alternatives should take hygienic aspects particularly into account.

Changing habitual consumption patterns in the context of plastic remains challenging. Perceived structural barriers, such as a lack of plastic-free alternatives for conventional products, are important to tackle when striving for behavioral change. However, psychological barriers, such as habits, have to be considered, too. To get people started, periods in which change is salient can help to disrupt people's daily routines. An arbitrary month such as 'Plastic Free July' has to be accepted as a good opportunity to become such a promising phase of change. Combining a phase of change with convenient offers (and providing information about them) to reduce barriers might be a good strategy for successful campaigns to encourage a reduction of single-use plastic consumption.

Supplementary Materials: The following are available online at http://www.mdpi.com/2071-1050/12/11/4698/s1, Data: Open Data.

Author Contributions: Conceptualization, L.M.H.; methodology, L.M.H.; formal analysis, L.M.H.; investigation, L.M.H.; data curation, L.M.H.; writing-original draft preparation, L.M.H.; writing-review and editing, J.S. and M.S.; visualization, L.M.H.; supervision, M.S.; project administration, M.S. All authors have read and agreed to the published version of the manuscript.

Funding: This research received no external funding.

Conflicts of Interest: The authors declare no conflict of interest.

\section{Appendix A}

Questionnaire

Survey I and II

Consumption $(1$ = 'not consumed', 2 = 'consumed' $)$ 
'Thinking of your last week: How many of these products have you consumed during the last week?'

Bh11: fruits \& vegetables (e.g., apples, carrots)

Bh12: fresh products (e.g., milk, yoghurt, sausage)

Bh13: dry products (e.g., noodles, cereals)

Bh14: beverages (e.g., juice, water, soft drinks)

Bh15: pastries (e.g., cake, bread)

Bh16: snacks (e.g., chips, chocolate)

Bh17: food to go (e.g., kebab, pizza)

Bh18: drinks to go (e.g., coffee-to-go, cola)

Bh19: cosmetics and sanitary products (e.g., deodorant, shower gel)

Bh110: household goods (e.g., detergent, cleaning agent)

Plastic consumption $(1=$ 'all without plastic', $2=$ 'partially in plastic', $3=$ 'all with plastic', NA = 'not bought at all')

'How much of your fruits and vegetables have you bought in plastic(packaging) during the last week (e.g., apples in a plastic bag)?'

Cat11a: pressure-sensitive fruit, e.g., berries

Cat12a: less pressure-sensitive fruit, e.g., apples

Cat13a: pressure-sensitive vegetables, e.g., tomatoes

Cat14a: less pressure-sensitive vegetables, e.g., pumpkins

'How much of your fresh products have you bought in plastic (packaging) during the last week (e.g., milk in a Tetra Pak)?'

Cat11b: milk products, e.g., milk, yoghurt, quark

Cat12b: milk substitute, e.g., oat milk, soy yoghurt

Cat 13b: cheese, cream cheese

Cat 14b: sausage, meat

Cat 15b: convenience food (e.g., tortellini)

'How much of your dry products have you bought in plastic(packaging) during the last week (e.g., cereals in plastic packaging)?'

Cat11c: side dishes and legumes, e.g., noodles, rice, millet, couscous, quinoa, lentils

Cat12c: cereals, e.g., muesli, oat flakes, cornflakes, amaranth

Car13c: nuts, nuts and raisins, dry fruits

Car14c: baking ingredients, e.g., flour, baking soda, vanilla sugar

Car15c: tea, coffee

'How much of your beverages have you bought in plastic(packaging) during the last week (e.g., PET-bottle)?'

Cat11d: water

Cat12d: juice

Cat13d: soft drinks, e.g., cola

Cat 14d: alcoholic drinks

'How much of your pastries have you bought in plastic(packaging) during the last week (e.g., pre-baked bread rolls in plastic packaging)?'

Cat11e: bread

Cat12e: bread rolls, baguettes

Cat13e: sweet pastries, cake

Cat14e: hearty pastries, e.g., pretzels

'How much of your snacks have you bought in plastic(packaging) during the last week (e.g., chocolate bar in plastic packaging)?'

Cat11f: sweets, e.g., bonbons

Cat12f: nibbles, e.g., chips 
'How much of your food on the go have you bought in plastic(packaging) during the last week (e.g., chocolate bar in plastic packaging)?'

Cat11g: hearty food, e.g., kebab

Cat12g: sweet food, e.g., ice cream

'How much of your drinks on the go have you bought in plastic(packaging) during the last week (e.g., coffee in a to-go mug)?'

Cat11h: hot drinks, e.g., coffee

Cat12h: cold drinks, e.g., cola

'How much of your cosmetics have you bought in plastic(packaging) during the last week (e.g., a plastic toothbrush or shampoo in a plastic bottle)?'

Cat11i: shampoo, soap, conditioner

Cat12i: make-up

Cat13i: deodorant, sanitary products

Cat14i: toothpaste, toothbrush

'How much of your housewares have you bought in plastic(packaging) during the last week (e.g., cleaning agent in a plastic bottle or a plastic dishwashing brush)?'

Cat11j: washing powder, detergent

Cat12j: cleaning agent

Cat13j: sponges, cleaning rags, brushes

Survey I

Perceived difficulty (from 1-'It's easy for me' to 5-'It's hard for me')

'How easy or difficult is it for you in daily life to consume the following products without plastic?'

Dif11: fruits \& vegetables

Dif12: fresh products

Dif13: dry products

Dif14: beverages

Dif15: pastries

Dif16: snacks

Dif17: food-to-go

Dif18: drinks-to-go

Dif19: cosmetics

Dif110: household goods

Problem awareness (from 1-'no problem' to 5-'very big problem')

'Do you consider the following aspects as very big problem, rather big problem, rather no problem or no problem?'

Pa11: plastic waste in the ocean

Pa12: plastic in soil

Pa13: species extinction through plastic in the environment

Pa14: aesthetic burden through plastic in the environment

Pa15: health impairment caused by plastic

Pa16: energy and resource use of plastic production

Pa17: increase of climate change from plastic

Pa18: social inequality in terms of plastic production and disposal

Pro-environmental identity (from 1-'strongly disagree' to 5-'strongly agree')

'How far do you agree with the following statement?'

Env: I see myself as an environmental conscious person.

Habits (from 1-'strongly disagree' to 5-'strongly agree')

'To buy products without plastic is something...'

$\mathrm{Hb} 11:$... I start doing before I realize I'm doing it.

Hb12: ... I do without having consciously remember. 
Hb13: ... that makes me feel weird. (r)

$\mathrm{Hb} 14:$... that requires effort. $(\mathrm{r})$

Hb15: ... I would find hard not to do.

Hb16: ... I do automatically.

Hb17: ... that's typically me.

Hb18: ... I do without thinking.

Intention [experimental group only] (from 1-'strongly disagree' to 5-'strongly agree')

'How far do you agree with the following statement?'

In1: I plan to reduce my plastic consumption during July.

Advices [experimental group only] ( 1 ='yes', 2 ='maybe', $3=$ ' $^{\prime} o^{\prime},-1=$ ' I' $^{\prime} m$ doing it already')

'We have different opportunities to reduce plastic consumption in daily life. Thinking about the next four weeks in July, will you try the following ideas?'

Tip11: taking a bag or rucksack

Tip12: drinking tapped water

Tip13: going to a zero-waste shop

Tip14: using wax cloth instead of plastic wrap

Tip15: using a menstrual cup

Tip16: using a wooden tooth-brush

Tip17: buying soap or shampoo in a piece

Tip18: using reusable dishes for barbecue

Tip19: buying milk or yoghurt in glass container

Tip110: producing food by oneself

Survey II

Perceived barriers (ranking: 1-strongest barrier up to 8-lowest barrier, NA $=$ not perceived as barrier)

'What keeps you from consuming (more) products without plastic in daily life? Please sort the following aspects. The strongest barrier should appear first. If an aspect does not represent a barrier to you, please leave it aside.'

Ba21: missing offers of plastic-free alternatives

Ba22: higher costs

Ba23: inconvenient transport

Ba24: missing hygiene

Ba25: time requirement

Ba26: limited shelf life

Ba27: too much interaction with the seller

Ba28: close circle that purchases differently

Policy support (from 1-'strongly disagree' to 5-'strongly agree')

'How far do you agree with the following statement?'

Ps21: I would use an app that shows plastic-free products.

Ps22: I would use a label that shows plastic-free products.

Ps23: I would use a deposit system for to-go-packaging (e.g., for pizza).

Ps24: I would use a deposit system for container at the counter (e.g., for cheese or sausage)

PS25: I would support a tax of single-use plastic products.

PS:26: I would support a ban of single-use plastic products (e.g., straws or balloons).

PS27: By political regulation, I feel restricted in my personal freedom.

\section{References}

1. Woodhouse, E.J. Curbing overconsumption: Challenge for ethically responsible engineering. IEEE Technol. Soc. Mag. 2001, 20, 23-30. [CrossRef] 
2. Brown, P.M.; Cameron, L.D. What can be done to reduce overconsumption? Ecol. Econ. 2000, 32, $27-41$. [CrossRef]

3. PlasticsEurope. Plastics—The Facts 2019. 2019. Available online: https://www.plasticseurope.org/de/ resources/publications/1804-plastics-facts-2019. (accessed on 18 March 2020).

4. Geyer, R.; Jambeck, J.R.; Law, K.L. Production, use, and fate of all plastics ever made. Sci. Adv. 2017, 3, ae1700782. [CrossRef]

5. Jambeck, J.R.; Geyer, R.; Wilcox, C.; Siegler, T.R.; Perryman, M.; Andrady, A.; Narayan, R.; Law, K.L. Plastic waste inputs from land into the ocean. Mar. Pollut. 2015, 347, 768-771. [CrossRef]

6. Cózar, A.; Fidel, E.; Ignacio, G.G.J.; Xabier, I.; Bárbara, U. Plastic debris in the open ocean. Proc. Natl. Acad. Sci. USA 2014, 111, 10239-10244. [CrossRef]

7. Thompson, R.C.; Moore, C.J.; Saal, F.S.V.; Swan, S.H. Plastics, the environment and human health: Current consensus and future trends. Philos. Trans. R. Soc. B Biol. Sci. 2009, 364, 2153-2166. [CrossRef]

8. Galloway, T.S.; Cole, M.; Lewis, C. Interactions of microplastics throughout the marine ecosystem. Nat. Ecol. Evol. 2017, 1, 1-8. [CrossRef]

9. Li, W.C.; Tse, H.F.; Fok, L. Plastic waste in the marine environment: A review of sources, occurrence and effects. Sci. Total Environ. 2016, 566, 333-349. [CrossRef]

10. Beaumont, N.J.; Aanesen, M.; Austen, M.C.; Börger, T.; Clark, J.R.; Cole, M.; Hooper, T.; Lindeque, P.K.; Pascoe, C.; Wyles, K.J. Global ecological, social and economic impacts of marine plastic. Mar. Pollut. Bull. 2019, 142, 189-195. [CrossRef]

11. Risch, S.J. Food Packaging History and Innovations. J. Agric. Food Chem. 2009, 57, 8089-8092. [CrossRef]

12. Hartley, B.L.; Pahl, S.; Veiga, J.; Vlachogianni, T.; Vasconcelos, L.; Maes, T.; Doyle, T.; Metcalfe, R.; Öztürk, A.A.; Di Berardo, M.; et al. Exploring public views on marine litter in Europe: Perceived causes, consequences and pathways to change. Mar. Pollut. Bull. 2018, 133, 945-955. [CrossRef] [PubMed]

13. European Commission. Proposal for a Directive of the European Parliament and of the Council on the Reduction of the Impact of Certain Plastic Products on the Environment; European Commission: Brussel, Belgium, 2018.

14. Heidbreder, L.M.; Bablok, I.; Drews, S.; Menzel, C. Tackling the plastic problem: A review on perceptions, behaviors, and interventions. Sci. Total Environ. 2019, 668, 1077-1093. [CrossRef] [PubMed]

15. Bates, C.H. Use of social marketing concepts to evaluate ocean sustainability campaigns. Soc. Mar. Q. 2010, 16, 71-96. [CrossRef]

16. Schultz, P.W. Strategies for promoting proenvironmental behavior: Lots of tools but few instructions. Eur. Psychol. 2014, 19, 107-117. [CrossRef]

17. Steg, L.; Vlek, C. Encouraging pro-environmental behaviour: An integrative review and research agenda. J. Environ. Psychol. 2009, 29, 309-317. [CrossRef]

18. Little, D. Rational-Choice Models and Asian Studies. J. Asian Stud. 1991, 50, 35-52. [CrossRef]

19. Ajzen, I. The theory of planned behavior. Organ. Behav. Hum. Decis. Process. 1991, 50, 179-211. [CrossRef]

20. Honkanen, P.; Verplanken, B. Understanding Attitudes Towards Genetically Modified Food: The Role of Values and Attitude Strength. J. Consum. Policy 2004, 27, 401-420. [CrossRef]

21. Honkanen, P.; Verplanken, B.; Olsen, S.O. Ethical values and motives driving organic food choice. J. Consum. Behav. 2006, 5, 420-430. [CrossRef]

22. Klöckner, C.A. A comprehensive model of the psychology of environmental behaviour-A meta-analysis. Glob. Environ. Chang. 2013, 23, 1028-1038. [CrossRef]

23. Schwartz, S.H. Normative influences on altruism. In Advances in Experimental Social Psychology; Berkowitz, L., Ed.; Academic Press: San Diego, CA, USA, 1977; pp. 221-279.

24. Bamberg, S.; Schmidt, P. Incentives, morality, or habit? Predicting students' car use for university routes with the models of Ajzen, Schwartz, and Triandis. Environ. Behav. 2003, 35, 264-285. [CrossRef]

25. Verplanken, B.; Wood, W. Interventions to Break and Create Consumer Habits. Am. Mark. Assoc. Assoc. 2006, 25, 90-103. [CrossRef]

26. Verplanken, B. Old Habits and New Routes to Sustainable Behaviour. In Engaging the Public with Climate Change; Whitmarsh, O., Lorenzoni, I., O’Neill, S., Eds.; Routledge: London, UK, 2012; pp. 43-56.

27. Bamberg, S. Is a residential relocation a good opportunity to change people's travel behavior? Results from a theory-driven intervention study. Environ. Behav. 2006, 38, 820-840. [CrossRef]

28. Heidbreder, L.M.; Schmitt, M. Fasting Plastic-An Intervention Study to break Habits of Plastic Consumption. Psyecology 2020. [CrossRef] 
29. Armitage, C.J.; Conner, M. Efficacy of the theory of planned behaviour: A meta-analytic review. Br. J. Soc. Psychol. 2001, 40, 471-499. [CrossRef]

30. Bamberg, S.; Möser, G. Twenty years after Hines, Hungerford, and Tomera: A new meta-analysis of psycho-social determinants of pro-environmental behaviour. J. Environ. Psychol. 2007, 27, 14-25. [CrossRef]

31. Chan, D.K.; Fishbein, M. Determinants of College Women's Intentions to Tell Their Partners to Use Condoms. J. Appl. Soc. Psychol. 1993, 23, 1455-1470. [CrossRef]

32. Cheung, S.F.; Chan, D.K.S.; Wong, Z.S.Y. Reexamining the theory of planned behavior in understanding wastepaper recycling. Environ. Behav. 1999, 31, 587-612. [CrossRef]

33. Thøgersen, J. How may consumer policy empower consumers for sustainable lifestyles? J. Consum. Policy 2005, 28, 143-177. [CrossRef]

34. Gifford, R. The Dragons of Inaction: Psychological Barriers That Limit Climate Change Mitigation and Adaptation. Am. Psychol. 2011, 66, 290-302. [CrossRef]

35. Bradu, C.; Orquin, J.L.; Thøgersen, J. The Mediated Influence of a Traceability Label on Consumer's Willingness to Buy the Labelled Product. J. Bus. Ethics 2014, 124, 283-295. [CrossRef]

36. Ariely, B.D.; Bracha, A.; Meier, S. Doing Good or Doing Well ? Image Motivation and Monetary Incentives in Behaving Prosocially. Am. Econ. Rev. 2009, 99, 544-555. [CrossRef]

37. Mazar, N.; Amir, O.; Ariely, D. The Dishonesty of Honest People: A Theory of Self-Concept Maintenance. J. Mark. Res. 2008, 45, 633-644. [CrossRef]

38. Rise, J.; Sheeran, P.; Hukkelberg, S. The role of self-identity in the theory of planned behavior: A meta-analysis. J. Appl. Soc. Psychol. 2010, 40, 1085-1105. [CrossRef]

39. Bolderdijk, J.W.; Steg, L.; Geller, E.S.; Lehman, P.K.; Postmes, T. Comparing the effectiveness of monetary versus moral motives in environmental campaigning. Nat. Clim. Chang. 2012, 3, 413-416. [CrossRef]

40. Dunning, D. Self-image motives and consumer behavior: How sacrosanct self-beliefs sway preferences in the marketplace. J. Consum. Psychol. 2007, 17, 237-249. [CrossRef]

41. Festinger, L. A Theory of Cognitive Dissonance; University Press: Stanford, CA, USA, 1957.

42. Thøgersen, J. Understanding repetitive travel mode choices in a stable context: A panel study approach. Transp. Res. Part A Policy Pract. 2006, 40, 621-638. [CrossRef]

43. Sparks, P.; Shepherd, R. Self-Identity and the Theory of Planned Behavior: Assesing the Role of Identification with 'Green Consumerism'. Am. Sociol. Assoc. 1992, 55, 388-399. [CrossRef]

44. Whitmarsh, L. Whitmarsh O’Neill (Green Identity) JEP 2010. J. Environ. Psychol. 2010, 44, 1-41.

45. Fielding, K.S.; McDonald, R.; Louis, W.R. Theory of planned behaviour, identity and intentions to engage in environmental activism. J. Environ. Psychol. 2008, 28, 318-326. [CrossRef]

46. Nigbur, D.; Lyons, E.; Uzzell, D. Attitudes, norms, identity and environmental behaviour: Using an expanded theory of planned behaviour to predict participation in a kerbside recycling programme. Br. J. Soc. Psychol. 2010, 49, 259-284. [CrossRef] [PubMed]

47. Terry, D.J.; Hogg, M.A.; White, K.M. The theory of planned behaviour: Self-Identity, social identity and group norms. Br. J. Soc. Psychol. 1999, 38, 225-244. [CrossRef] [PubMed]

48. De Groot, J.I.M.; Steg, L. Mean or green: Which values can promote stable pro-environmental behavior? Conserv. Lett. 2009, 2, 61-66. [CrossRef]

49. Whitmarsh, L.; Capstick, S.; Nash, N. Who is reducing their material consumption and why? A cross-cultural analysis of dematerialization behaviours. Philos. Trans. R. Soc. A Math. Phys. Eng. Sci. 2017, 375, 20160376. [CrossRef] [PubMed]

50. Jager, W. Breaking 'bad habits': A dynamical perspective on habit formation and change. In Human Decision Making and Environmental Perception. Understanding and Assisting Human Decision Making in Real-Life Settings; Hendrickx, L., Jager, W., Steg, L., Eds.; University Of Groningen: Groningen, The Netherlands, 2003.

51. Klöckner, C.A.; Blöbaum, A. A comprehensive action determination model: Toward a broader understanding of ecological behaviour using the example of travel mode choice. J. Environ. Psychol. 2010, 30, 574-586. [CrossRef]

52. Gkargkavouzi, A.; Halkos, G.; Matsiori, S. Environmental behavior in a private-sphere context: Integrating theories of planned behavior and value belief norm, self-identity and habit. Resour. Conserv. Recycl. 2019, 148, 145-156. [CrossRef] 
53. Kurz, T.; Gardner, B.; Verplanken, B.; Abraham, C. Habitual behaviors or patterns of practice? Explaining and changing repetitive climate-relevant actions. Wiley Interdiscip Rev. Clim. Chang. 2015, 6, 113-128. [CrossRef]

54. Schäfer, M.; Jaeger-Erben, M.; Bamberg, S. Life Events as Windows of Opportunity for Changing Towards Sustainable Consumption Patterns? J. Consum. Policy 2012, 35, 65-84. [CrossRef]

55. Verplanken, B.; Habit, H.A. attitude, and planned behaviour: Is habit an empty construct or an interesting case of goal-directed automaticity? Eur. Rev. Soc. Psychol. 1999, 10, 101-134. [CrossRef]

56. Fuji, S.; Gärling, T. Development of script-based travel mode choice after forced change. Transp. Res. Part F Traffic Psychol. Behav. 2003, 6, 117-124. [CrossRef]

57. Thøgersen, J.; Møller, B. Breaking car use habits: The effectiveness of a free one-month travelcard. Transportation (Amst.) 2008, 35, 329-345. [CrossRef]

58. Verplanken, B.; Roy, D. Sustainable Consumption. Elgar Original Reference. Edward Opus: University of Bath Online Publication Store 15. Consumer Habits and Sustainable Consumption; Edward Elgar Publishing Limited: Cheltenham, UK, 2015; pp. 243-253.

59. Haggar, P.; Whitmarsh, L.; Skippon, S.M. Habit discontinuity and student travel mode choice. Transp. Res. Part F Traffic Psychol. Behav. 2019, 64, 1-13. [CrossRef]

60. Müggenburg, H.; Busch-Geertsema, A.; Lanzendorf, M. Mobility biographies: A review of achievements and challenges of the mobility biographies approach and a framework for further research. J. Transp. Geogr. 2015, 46, 151-163. [CrossRef]

61. Thomas, G.O.; Poortinga, W.; Sautkina, E. Habit discontinuity, self-activation, and the diminishing influence of context change: Evidence from the UK understanding society survey. PLoS ONE 2016, 11, e0153490. [CrossRef] [PubMed]

62. Verplanken, B.; Walker, I.; Davis, A.; Jurasek, M. Context change and travel mode choice: Combining the habit discontinuity and self-activation hypotheses. J. Environ. Psychol. 2008, 28, 121-127. [CrossRef]

63. Gillison, F.; Standage, M.; Verplanken, B. A cluster randomised controlled trial of an intervention to promote healthy lifestyle habits to school leavers: Study rationale, design, and methods. BMC Public Health 2014, 14, 221. [CrossRef] [PubMed]

64. Thomas, G.O.; Fisher, R.; Whitmarsh, L.; Milfont, T.L.; Poortinga, W. The impact of parenthood on environmental attitudes and behaviour: A longitudinal investigation of the legacy hypothesis. Popul. Environ. 2018, 39, 261-276. [CrossRef] [PubMed]

65. Walker, I.; Thomas, G.O.; Verplanken, B. Old Habits Die Hard: Travel Habit Formation and Decay During an Office Relocation. Environ. Behav. 2015, 47, 1089-1106. [CrossRef]

66. Schäfer, M.; Bamberg, S. Breaking habits: Linking sustainable consumption campaigns to sensitive life events. In Proceedings of the Sustainable Consumption and Production: Framework for Action, Conference of the Sustainable Consumption Research Exchange, Brussels, Belgium, 10-11 March 2008; pp. 213-228.

67. Verplanken, B.; Roy, D. Empowering interventions to promote sustainable lifestyles: Testing the habit discontinuity hypothesis in a field experiment. J. Environ. Psychol. 2016, 45, 127-134. [CrossRef]

68. Vermeir, I.; Verbeke, W. Sustainable food consumption among young adults in Belgium: Theory of planned behaviour and the role of confidence and values. Ecol. Econ. 2008, 64, 542-553. [CrossRef]

69. Tonglet, M.; Phillips, P.S.; Read, A.D. Using the Theory of Planned Behaviour to investigate the determinants of recycling behaviour: A case study from Brixworth, UK. Resour. Conserv. Recycl. 2004, 41, 191-214. [CrossRef]

70. Stern, P.C. Toward a Coherent Theory of Environmentally Significant Behavior. J. Soc. Issues 2000, 56, 407-424. [CrossRef]

71. Zhao, J. Communication: Influencing policymakers. Nat. Clim. Chang. 2017, 7, 173-174. [CrossRef]

72. Xanthos, D.; Walker, T.R. International policies to reduce plastic marine pollution from single-use plastics (plastic bags and microbeads): A review. Mar. Pollut. Bull. 2017, 118, 17-26. [CrossRef] [PubMed]

73. Ritch, E.; Brennan, C.; MacLeod, C. Plastic bag politics: Modifying consumer behaviour for sustainable development. Int. J. Consum. Stud. 2009, 33, 168-174. [CrossRef]

74. Leiner, D.J. SoSci Survey (Version 2.6.00) [Computer Software]. 2016. Available online: https://www.soscisurvey. de (accessed on 18 March 2020). 
75. Umweltbundesamt (UBA). Umweltbewusstsein in Deutschland 2016. Available online: https: //www.umweltbundesamt.de/sites/default/files/medien/376/publikationen/umweltbewusstsein deutschland_2016_bf.pdf (accessed on 18 March 2020).

76. Verplanken, B.; Orbell, S. Reflections on Past Behavior: A Self-Report Index of Habit Strength1. J. Appl. Soc. Psychol. 2003, 33, 1313-1330. [CrossRef]

77. Vandenberg, R.J.; Lance, C.E. A Review and Synthesis of the Measurement Invariance Literature: Suggestions, Practices, and Recommendations for Organizational Research. Organ. Res. Methods 2000, 3, 4-70. [CrossRef]

78. Revelle, W. Psych: Procedures for Psychological, Psychometric, and Personality Research; Northwestern University: Evanston, IL, USA, 2014; Volume 165, p. 1-10e.

79. Wickham, H.; Averick, M.; Bryan, J.; Chang, W. Welcome to the Tidyverse. J. Open Source Softw. 2019, 4, 1686. [CrossRef]

80. Rosseel, Y. lavaan: An R Package for Structural Equation Modeling. J. Stat. Softw. 2012, 48, 1-36. [CrossRef]

81. Fox, J.; Nie, Z.; Byrnes, J.; Culbertson, M.; DebRoy, S.; Friendly, M.; Goodrich, B.; Jones, R.H.; Kramer, A.; Monette, G.; et al. Package 'sem'. 2017. Available online: https://mran.microsoft.com/snapshot/2016-10-12/ web/packages/sem/sem.pdf (accessed on 18 March 2020).

82. Bryła, P. Organic food consumption in Poland: Motives and barriers. Appetite 2016, 105, 737-746. [CrossRef]

83. Van Doorn, J.; Verhoef, P.C. Drivers of and barriers to organic purchase behavior. J. Retail. 2015, 91, 436-450. [CrossRef]

84. Vittersø, G.; Tangeland, T. The role of consumers in transitions towards sustainable food consumption. The case of organic food in Norway. J. Clean. Prod. 2015, 92, 91-99. [CrossRef]

85. Allen, M.; Clifford, J.; Atkinson, D. Exploring consumers reliance on plastic in fresh food packaging: Adding to the waste? In Proceedings of the 39th International Scientific Conference on Economic and Social Development-Sustainability from an Economic and Social Perspective, Lisbon, Portugal, 29-30 April 2019; pp. 15-27.

86. Aarts, H.; Verplanken, B.; Van Knippenberg, A. Predicting Behavior From Actions in the Past: Repeated Decision Making or a Matter of Habit? J. Appl. Soc. Psychol. 1998, 28, 1355-1374. [CrossRef]

87. Verplanken, B.; Aarts, H.; Van Knippenberg, A. Habit, information acquisition, and the process of making travel mode choices. Eur. J. Soc. Psychol. 1997, 27, 539-560. [CrossRef]

88. Olivos, P.; Aragonés, J.I. Psychometric properties of theEnvironmental Identity Scale (EID). Psyecology 2011, 2, 65-74. [CrossRef]

89. Whitmarsh, L.E.; Haggar, P.; Thomas, M. Waste reduction behaviors at home, at work, and on holiday: What influences behavioral consistency across contexts? Front. Psychol. 2018, 9, 2447. [CrossRef] [PubMed]

90. Arnold, O.; Kibbe, A.; Hartig, T.; Kaiser, F.G. Capturing the Environmental Impact of Individual Lifestyles: Evidence of the Criterion Validity of the General Ecological Behavior Scale. Environ. Behav. 2018, 50, 350-372. [CrossRef]

91. Kaiser, F.G.; Wilson, M. Goal-directed conservation behavior: The specific composition of a general performance. Pers. Individ. Dif. 2004, 36, 1531-1544. [CrossRef]

92. Freedman, J.I.; Fraser, S.C. Compliance Without Pressure. J. Pers. Soc. Psychol. 1966, 4, 195-202. [CrossRef]

93. Bamberg, S. Applying the stage model of self-regulated behavioral change in a car use reduction intervention. J. Environ. Psychol. 2013, 33, 68-75. [CrossRef]

94. Veiga, J.M.; Vlachogianni, T.; Pahl, S.; Thompson, R.C.; Kopke, K.; Doyle, T.K.; Hartley, B.L.; Maes, T.; Orthodoxou, D.L.; Loizidou, X.I.; et al. Enhancing public awareness and promoting co-responsibility for marine litter in Europe: The challenge of MARLISCO. Mar. Pollut. Bull. 2016, 102, 309-315. [CrossRef] [PubMed]

95. Synthia, I.J.; Kabir, S. An Investigation of Consumer Attitudes Towards New Varieties of Shopping Bags: Exploring Eco-Awareness and the Possibility of Behavior Change. J. Dev. Areas 2015, 49, 183-196. [CrossRef]

96. Beitzen-Heineke, E.F.; Balta-Ozkan, N.; Reefke, H. The prospects of zero-packaging grocery stores to improve the social and environmental impacts of the food supply chain. J. Clean. Prod. 2017, 140, 1528-1541. [CrossRef]

(C) 2020 by the authors. Licensee MDPI, Basel, Switzerland. This article is an open access article distributed under the terms and conditions of the Creative Commons Attribution (CC BY) license (http://creativecommons.org/licenses/by/4.0/). 